\title{
A DINÂMICA SUBJACENTE AO PROCESSO DE HUMANIZAÇÃO DA PRÁTICA DO ENFERMEIRO DO TRABALHO
}

\section{THE DYNAMICS RELATED TO THE HUMANIZATION THE PRACTICAL ON NURSING WORK}

\author{
Marilei de Melo Tavares e Souza \\ Escola de Enfermagem da Universidade Federal Fluminense/UFF e Universidade Severino Sombra/USS \\ marileimts@hotmail.com
}

\begin{abstract}
Resumo
O presente estudo buscou analisar o trabalho da enfermagem em sua dinâmica subjacente ao processo de humanização, partindo de uma estratégia de ensino que visava promover reflexão sobre o processo de trabalho de enfermagem. Realizou-se um estudo exploratório de campo, de abordagem qualitativa com os alunos do Curso de Especialização em Enfermagem do Trabalho. Recorreu-se a técnica de dramatização como modo de expressão de experiências geradoras de sofrimento no ambiente de trabalho. Verificou-se, com os resultados do estudo, que os métodos empregados pelo enfermeiro em seu cotidiano de trabalho são de orientação tecnicista, marca de sua formação. Tais métodos produzem como efeito um cuidar tardio/descuidado e a negação do sofrimento, tanto dos trabalhadores como dos pacientes. Conclui-se que dinâmica subjacente ao processo de cuidar dos enfermeiros em seu cenário de prática é marcada por faltas que simbolizam a carência histórica de valorização social da profissão de enfermagem.
\end{abstract}

Palavras-chave: Enfermagem; Humanização; Formação; Saúde do Trabalhador.

\begin{abstract}
The present study analyzes the nursing work and its dynamics related to the humanization process, having as a point of view one education strategy whose aim promotes reflection on nursing work. This empirical and qualitative research has as subject pupils of the Specialization Course in Occupational Nursing. Dramatization was the technique used to express the experiences of suffering in the work environment. Through these results, is the methods used for the nurse in its daily work are of technical oriented as a education mark. Such methods produce as effect the late/carelessness emergency care and the suffering refusal in workers and patients. One concludes that dynamic underlying the nurses' care process in its practical work scene is marked by lack that symbolize the historical lack of social valuation in nursing profession.
\end{abstract}

Key-words: Nursing; Humanization; Formation; Occupational Health 


\section{Introdução}

Cada vez mais pesquisas e programas têm apontado para a melhoria das práticas em saúde. O Programa Nacional de Humanização da Assistência Hospitalar (PNHAH) é um exemplo dessa tentativa de qualificar o cuidado em saúde. Deste modo, é preciso dar voz aos atores sociais que desenvolvem o processo de cuidar dos serviços de saúde, escutar seu sofrimento para que não repercuta negativamente em sua prática e no processo de humanização dos cuidados. Para tanto, urge acolher a subjetividade manifestada no coletivo dos profissionais de saúde e na intersubjetividade de suas relações (BRASIL, 2002).

Compreendemos que humanização refere-se às práticas concretas dos serviços de saúde, à melhoria da qualidade de vida dos usuários e à melhoria das condições de trabalho dos profissionais de saúde. A humanização depende da capacidade de falar e de ouvir. Ao se tentar promover a humanização dos serviços de saúde, há necessidade de se incluir todas as dimensões da subjetividade do usuário - psíquicas, familiares, culturais e sociais -, bem como as dos profissionais também devem ser consideradas. Assim, considerar essas dimensões significa permitir e oferecer a eles melhores condições para enfrentar o desgaste provocado pelo constante contato com a dor, com o sofrimento, com os limites e as dificuldades na realização do seu trabalho. A humanização é um eficiente instrumento de compreensão e manutenção da saúde do usuário e do profissional diante das exigências de seu trabalho. Ou seja, o PNHAH se propõe a uma ação política, que implica novas relações no ambiente de trabalho, isto é, um novo operador ético, pois não mudamos as formas de atender a população sem que as organizações dos processos de trabalho também se modifiquem. E é exatamente essa dinâmica de interação em uma equipe de Saúde que aqui será analisada na "voz" do profissional de Enfermagem. A aproximação com o discurso da Psicologia se dá pelo fato de que essas "vozes" estão sendo analisadas a partir da idéia de que os atores envolvidos nas práticas de saúde são sujeitos do processo de produção de verdade no cenário em que estão implicados.

Nesta perspectiva, há preocupação com o conteúdo simbólico, com seus conteúdos invisíveis, com as relações subjetivas que os profissionais estão sujeitos no cenário de prática, como o sofrimento e, conseqüentemente, o desgaste ocasionado pelo processo de trabalho e, sobretudo, as consequiências sobre a saúde biopsicossocial dos sujeitos envolvidos com o cenário da saúde. 
Visando intervir nas situações do processo de trabalho e tentar entender os processos psíquicos ali inseridos e apontar novos rumos para esse sofrimento, além de acompanhar o sujeito em seu processo de trabalho, é passo fundamental entender, sobretudo, seu processo de vida. Na busca de soluções para a melhoria da qualidade de vida no trabalho devem ser abordados elementos relacionados à organização e fatores psicossociais do trabalho, comumente excluídos do leque de ações em saúde no trabalho. Uma marca do cuidar revelado pela enfermagem é a presença capaz de produzir efeitos terapêuticos. A profissão de enfermagem, no conjunto das demais profissões de saúde, é pautada na presença, na permanência, na continuidade do trabalho e não na visita. A jornada de trabalho das enfermeiras é exaustiva, por isso embora propicie um contato mais prolongado com o paciente, nem sempre assegura um cuidado humanizado.

Humanizar é garantir à palavra a sua dignidade ética. Ou seja, o sofrimento humano, as percepções de dor ou de prazer no corpo para serem humanizadas precisam tanto que as palavras com que o sujeito as expressa sejam reconhecidas pelo outro, quanto esse sujeito precisa ouvir do outras palavras de seu reconhecimento. Pela linguagem fazem-se as descobertas de meios pessoais de comunicação com o outro, sem o que se desumaniza reciprocamente (OLIVEIRA et al, 2006 p.280).

Trabalhar integralmente questões relacionadas à prática do profissional de saúde enfatizando o processo de trabalho, a humanização no cuidado e sua formação é um passo fundamental para se desenvolver novas abordagens teórico-metodológicas que possibilitem avançar nos processos de análise e intervenção sobre as situações, impactos e efeitos que são submetidos os enfermeiros em seu cenário de prática.

\section{O sofrimento repercutido através do cuidado}

Formados dentro de uma visão que privilegia a biologia e a anatomia como matérias básicas, os profissionais de saúde tendem a considerar os pacientes como seres ahistóricos e desprovidos de um saber, o que gera no cotidiano de seu trabalho um agir técnico, descontextualizado e descomprometido com atividades de educação em saúde e prestação de uma singularidade junto ao paciente e sua família (CECCIM \& FEUERWERKER, 2004).

Para Zozaya (1985), o diagnóstico, ou melhor, as enfermidades produzem uma série de conflitos emocionais, ansiedade e angústia, que vão desencadear no paciente uma série de mecanismos defensivos múltiplos, interferindo também no sentido do 
cuidado recebido. Entre os mais freqüentes estão a regressão, a negação e a intelectualização.

Com a internação, o paciente percebe que não é o mesmo, pois há uma ruptura na história deste, ocasionando sofrimento diante de sua própria imagem, já alterada. Sabe-se que, apesar de dar a retaguarda, o hospital tem uma função separadora: internado, o paciente fica sozinho e tem que aceitar as normas impostas pelo hospital (SANTOS et al., 1996).

Assim, a doença é sentida pelo indivíduo como uma agressão, gerando um abalo na condição de ser, tornando o futuro incerto. A doença na vida do indivíduo instala-se de uma maneira abrupta, não permitindo ao ser humano uma adaptação gradativa à nova situação. O próprio agravamento de determinados processos de hospitalização se processa mais no imaginário do paciente do que no processo hospitalar.

As perdas sentidas como definitivas, impostas como conseqüência da doença, são traduzidas por uma privação ao nível do funcionamento e do prazer corporal. Muitas vezes essas perdas são equivalentes à perda de um objeto de amor e acarretam as mesmas reações de certo. A vida gira agora em função da doença, o mundo torna-se vazio, desinteressante, pobre. Um desânimo profundo, uma inibição de toda e qualquer atividade (LIMA; MENDONÇA; DENIZ, 1994).

Percebe-se que uma série de sentimentos confusos e dolorosos pode acompanhar o indivíduo a partir do aparecimento da doença e se agravar com a internação hospitalar. A internação reforça a condição de dependência, que pode ser sentida pelo paciente como agressão, pois se encontra sobre o domínio de uma estrutura hospitalar, sob o poder dos profissionais de saúde, que muitas vezes tiram o sentido de autonomia e a capacidade de decisão do paciente.

\section{A Enfermagem e a formação atual}

A enfermagem moderna no Brasil nasce sob a égide da saúde pública. A primeira escola no Brasil a ministrar o ensino sistematizado de enfermagem - Escola Ana Néri (1923) - privilegiava em seu currículo disciplinas de caráter preventivo em consonância com exigência política da época. A partir dos anos 50, houve uma forte tendência para o campo hospitalar. Nos anos 70, em decorrência da monopolização da economia, as práticas de saúde e o exercício da medicina e da enfermagem sofreram um processo acentuado de privatização e de especialização excessivas. Essa privatização 
diz respeito à crescente organização empresarial de que se reveste a prestação da assistência médica (GERMANO, 1985).

A saúde tomada pelo ponto de vista biologicista, centrado na doença, na hegemonia médica, na atenção individual e na utilização intensiva de tecnologia, cuidado, na ação intersetorial e na crescente autonomia das populações em relação à saúde é colocada em questão.

A VIII Conferência Nacional de Saúde visou a Reforma Sanitária, propondo mudanças no modelo tradicional de atenção em saúde, requerendo transformações na formação e nas práticas do profissional de saúde. Tendo como proposta o atendimento integral à promoção, proteção e recuperação da saúde. Nesta perspectiva, o papel do enfermeiro não está limitado à prestação direta de cuidados ou à supervisão de técnicos e auxiliares. O enfermeiro passa a exercer funções de coordenação, ensino e supervisão no campo da saúde. Devendo, portanto, ser preparado para operar vários modelos que venham qualificá-lo para exercer múltiplas funções, contribuindo para a qualidade do atendimento em todos os níveis da assistência à saúde (ALMEIDA, 1986).

O modelo de formação do enfermeiro instruído pela pedagogia tecnicista foi questionado pelo conjunto social da profissão a partir do final da década 80. Exaustivos debates, seminários e discussões de âmbito nacional no contexto da enfermagem, culminaram com a Portaria MEC1721/94, que visou corrigir distorções indispensáveis ao processo de formação do enfermeiro, adequando este processo às transformações da profissão da área de saúde, de ensino, do mercado de trabalho e principalmente às necessidades e demandas de saúde da população, expressas pela significante mudança no seu perfil demográfico e epidemiológico (TAVARES, 2002b).

Contudo, segundo Deluiz (2001), o modelo de currículo previsto na referida portaria guarda relação com perspectiva e abordagem contemporâneas de formação, as quais se encontram atreladas ao quadro de mundialização da economia, de exacerbação da competição nos mercados e de demandas de melhoria da qualidade dos produtos e de flexibilização dos processos de produção e de trabalho, onde a aprendizagem é orientada para a ação e a avaliação das competências, que buscam adaptar o profissional às novas exigências do mercado de trabalho.

A garantia de uma formação integral do enfermeiro implica no aprofundamento necessário do conhecimento em sua dimensão científica e histórica, compartilhada em experiências com práticas coletivas, que abranjam a dimensão de 
cidadania, a fim de superar definitivamente a prática profissional instrumentadora, tecnicista e acrítica. Contudo, a mudança no modelo de formação do enfermeiro passa pela necessidade de transformação do próprio sistema de saúde. Hoje, embora possamos observar sinais de reorientação do modelo assistencial, representado pelas experiências do Sistema Único de Saúde (SUS) em alguns municípios e do Programa Saúde da Família (PSF), que procuram romper com a lógica produtivista dos serviços e implantam práticas fundadas no conceito mais abrangente de saúde, constatamos no atual sistema, os déficits qualitativos e quantitativos de atenção à saúde.

$\mathrm{Na}$ atualidade há uma tendência nas instituições formadoras de enfermeiros de reconhecer que faz parte do papel profissional do enfermeiro pensar na responsabilidade social para a locação de recursos; garantir o direito à saúde da população e promover processos participativos que estimulem a organização popular. Contudo, a prática profissional de enfermagem ainda é marcada por uma atuação centrada no cenário hospitalar e na utilização intensiva de tecnologia (TAVARES, 2002b).

\section{Sobre o cuidar em enfermagem}

O cuidado em enfermagem se sustenta na interação humana e social, na relação dialógica de interação recíproca entre o enfermeiro e o sujeito cuidado, na qual se desenrola um intercâmbio de processos de vida e uma maneira particular de entender a saúde, a enfermidade e a morte. Esta interseção sujeito-cuidado é onde a comunicação em sua forma verbal, gestual, atitudes e afeto se constituem no cenário para o encontro com o outro, onde decidir resulta em um elemento fundamental para o cuidado.

Watson (1979) descreve a enfermagem inserida em um contexto de ciência humana e de arte; a enfermagem e paciente dentro de um contexto de intersubjetividade; os relacionamentos de cuidado humano na enfermagem como um ideal moral. Ela conceitua o cuidado como um esforço transpessoal do ser humano no sentido de proteger, promover e preservar a humanidade, através do auxílio às pessoas para que encontrem significado na doença, sofrimento, dor, bem como na existência.

A essência do cuidar para a enfermagem é um processo de interação sujeitosujeito dirigido ao cuidado, apoiar e acompanhar os indivíduos, com acolhimento para a recuperação da saúde, mediante realização de suas necessidades humanas fundamentais. Para tal é preciso que o enfermeiro desempenhe um papel que corresponde com a aplicação de valores humanos e integrais de sua profissão. O enfermeiro nutre-se de outras ciências e acumula habilidades, experiências e informações ao redor do trabalho. 
Para poder transformar a prática do enfermeiro, fazendo dela uma prática de natureza ética, deve-se: escutar os pacientes, facilitar a empatia, favorecer a autonomia e promovê-los como sujeitos ativos de seu cuidado (ADRIGHETTI, 2005).

Hoje, para a implementação do cuidado com ações humanizadoras, torna-se indispensável valorizar a dimensão subjetiva e social em todas as práticas de atenção e gestão no SUS, fortalecer o trabalho em equipe multiprofissional, fomentar a construção de autonomia e protagonismo dos sujeitos, fortalecer o controle social com caráter participativo em todas as instâncias gestoras do SUS, democratizar as relações de trabalho e valorizar os profissionais de saúde. Ao apresentar essa proposta, o Programa Nacional da Assistência Hospitalar insere a dimensão humana e subjetiva, na base de toda intervenção em saúde, das mais simples às mais complexas, influenciando na eficácia dos serviços prestados pelos hospitais (OLIVEIRA et. al, 2006).

A conduta dos profissionais de Enfermagem é um fator determinante e de preocupação para muitos estudiosos dos processos de humanização na saúde. A razão instrumental abre espaço para a razão sensível e o sentido profundo. Deste modo, o enfermeiro pode compreender melhor a dimensão da alteridade, do acolhimento e da reciprocidade.

Segundo Trevisan et al (2003), a sensibilidade fundamental do cuidado emerge quando o sujeito sai de si em busca do outro, sente-se como o outro - coloca-se em seu lugar - participa de sua existência, deixando-se tocar por sua história. Portanto, através da razão sensível do sentido profundo, a enfermagem passa a compreender melhor a dimensão do acolhimento no ato de cuidar.

\section{A Humanização na assistência}

Muitos estudos têm investido em pesquisas que destacam a humanização da assistência na saúde, exemplo de Collet (2003), Deslandes (2004), Ferreira et.al (2004), Benevides et al. (2005), Gastaldo (2005), entre outros. Esses estudos discutem a humanização da assistência e principais dilemas e processos conflituosos do Programa Nacional de Humanização da Assistência Hospitalar.

Em 2001, o Ministério da Saúde cria o PNHAH, tendo como objetivo mais amplo a humanização da assistência, visando à melhoria da qualidade do atendimento público à saúde e a valorização do trabalho dos profissionais. O PNHAH propõe um conjunto de ações integradas que visam mudar substancialmente o padrão da assistência 
ao usuário dos serviços, melhorando a qualidade e a eficácia dos serviços. O PNHAH tem como objetivos: aprimorar as relações entre profissional de saúde e usuário, dos profissionais entre si e do hospital com a comunidade; difundir uma nova cultura de humanização na rede pública hospitalar; melhorar a qualidade e a eficácia de atenção dispensada aos usuários; capacitar os profissionais para um novo conceito da assistência à saúde que valorize a vida humana e a cidadania. Tem como um dos planos de intervenção - no plano subjetivo - sustentar um processo de reflexão contínua sobre as vivências no mundo do trabalho.

A unidade de saúde tem como objetivo oferecer um atendimento de qualidade à população. Mas, para que isso aconteça, é necessário pensar em um conjunto de ações capaz de atender a três dimensões: a humanização do atendimento ao usuário; a humanização das condições de trabalho do profissional de saúde e o atendimento da instituição hospitalar em suas necessidades básicas administrativas, físicas e humanas.

Ao se tentar promover a humanização dos serviços de saúde, há necessidade de incluir todas as dimensões da subjetividade do usuário - psíquicas, familiares, culturais e sociais -, bem como as dos profissionais também devem ser consideradas. Assim, considerar essas dimensões significa permitir oferecer a ele melhores condições de enfrentar o desgaste provocado pelo constante contato com a dor, com o sofrimento e com limites e dificuldades na realização do seu trabalho. Ao respeitar aspectos subjetivos existentes na atividade profissional, se constitui uma proteção à saúde, permitindo-lhe agir de modo menos defensivo, mais espontâneo e próximo às suas carências e às dos usuários.

A humanização dos serviços de saúde envolve três aspectos fundamentais: a capacitação permanente dos profissionais de saúde e a criação de condições para que participe efetivamente na identificação das melhorias que considerem necessárias às suas condições de trabalho; a criação de condições para que o usuário participe na avaliação da qualidade dos serviços que lhe são oferecidos e o empenho da comunidade organizada e sua efetiva participação como parceira dos agentes públicos de saúde, em ações de apoio e acompanhamento dos serviços. É a possibilidade de se colocar no lugar do outro, de abrir espaço para que o outro saiba algo que não se sabe de antemão, e isso depende de se aceitar que todo saber é limitado: algo que não se sabe e que, portanto, poderá vir de outro. 


\section{A necessidade de mudança na temática humanização}

A humanização da assistência congrega demandas antigas por democratização, por melhoria na comunicação interpessoal do profissional de saúde e o paciente. Redimensiona papéis, rediscute o modelo assistencialista. A humanização, além de prezar pela equipe de saúde saudável - com ações direcionadas -, abre espaço e valoriza canais de negociação, favorecendo uma nova postura profissional. Entretanto, a humanização muitas vezes é confundida com assistencialismo, suas diretrizes muitas vezes são mal interpretadas, assim como a própria questão do cuidar em saúde.

Para ganhar a força necessária que dê direção a um processo de mudança, Benevides et.al (2006) refere que para que isso aconteça, a humanização impõe enfrentamento de dois desafios: conceitual, em que o conceito de humanização ao ganhar destaque em Programas no campo da Saúde Pública - modismo - padroniza ações e repete modos de funcionar de forma sintomática. Com isso a humanização ganha, no início dos anos 2000, um aspecto de 'conceito-sintoma' - paralisa e reproduz um sentido já dado. Para os autores, humanização, enquanto 'conceito-sintoma', está presente nas práticas de atenção segmentadas por áreas: saúde da mulher, saúde da criança, saúde do idoso e assistência hospitalar; identificadas ao exercício de certas profissões - assistência social, psicólogo e característica de gênero; orientadas por exigências de mercado que devem focar o cliente e garantir qualidade total nos serviços. Sobre o conceito de humanização, este deve ganhar outra amplitude quando estamos conscientes de que não serve esse esforço conceitual se isso não resultar em alteração nas práticas concretas dos serviços de saúde, na melhoria da qualidade de vida dos usuários e na melhoria das condições de trabalho dos profissionais da saúde. Não basta defender o caráter específico e concreto das práticas de humanização.

Ao se realizar mudanças nos processos de produção de saúde, tornam-se indispensáveis igualmente mudanças no processo de subjetivação. A humanização, como política de saúde, se constrói com as direções de inseparabilidade entre atenção, gestão e da transversalidade. Mudamos as relações no campo da saúde quando experimentamos a inseparabilidade entre as práticas do cuidado e da gestão do cuidado. Cuidar e gerir os processos de trabalho em saúde compõem, na verdade, uma só realidade. Por outro lado, não há como mudar as formas de relacionamento nas práticas de saúde sem que aumentemos os graus de comunicação, de conectividade e intercessão intra e intergrupos - transversalidade. 
Em sua prática diária, o profissional de saúde deve valorizar os sentimentos despertados em seu cotidiano e incorporá-los como instrumentos valiosos no atendimento à saúde. Quando em contato com o outro, são inevitáveis sentimentos como afeição, respeito, simpatia, empatia, angústia, raiva, medo, erotismo, compaixão. Para que haja profissionalismo e bom atendimento, esses aspectos precisam ser reconhecidos, estar sob controle e a serviço da compreensão das necessidades dos usuários e profissionais. Quando incorporados adequadamente à atividade do profissional, esses sentimentos podem se tornar instrumentos valiosos no atendimento à saúde. Da mesma forma, é fundamental considerar os aspectos de condições de vida, de condições de trabalho, de relações familiares, culturais e sociais, o que pode contribuir para o cuidado do usuário e o restabelecimento do seu bem-estar. A humanização depende da capacidade de falar e de ouvir.

A humanização é um eficiente instrumento de compreensão e manutenção da saúde do usuário e do profissional diante das exigências de seu trabalho. Humanizar, neste sentido, é alcançar benefícios mútuos para a saúde do usuário e do profissional. Contudo, depende do estabelecimento de estratégias que favorecem uma prática comprometida, que permita falar da angústia. O reconhecimento dos problemas que afetam a saúde física e mental do profissional de saúde proporcionará novos estímulos e motivação para estabelecer a relação de ajuda com o paciente. Quanto mais preparada a equipe de saúde estiver para compreender o seu próprio comportamento e suas emoções, mais confiança terá para responder aos desafios das necessidades emocionais de seus pacientes. Mas, para que se torne um dispositivo de recuperação e manutenção da saúde, não bastam intuição e boa vontade. Precisa-se incluí-la sistematicamente na prática profissional, com critérios e métodos a serem permanentemente avaliados. Ela envolve necessariamente o trabalho conjunto de diferentes profissionais em todos os níveis de atendimento.

Ayres (2006), sobre o cuidado e as perspectivas de humanização em saúde, refere que podemos e devemos fugir de uma prática 'dessubjetivadora', ou seja, de uma interação tão obcecada pelo objeto de intervenção que deixe de perceber e aproveitar as trocas mais amplas que se realizam no cenário. Ao considerarmos esse outro saber, assumimos que a saúde e a doença são apenas objetos. Portanto, revalorizar a dignidade dessa sabedoria prática é uma tarefa e um compromisso fundamental quando se quer cuidar, ao deixar a pessoa assistida participar da ação. É aí que está presente a importância do cuidar nas práticas de saúde: o desenvolvimento de atitudes e espaços de 
genuíno encontro intersubjetivo, de exercício de uma sabedoria prática para a saúde. Um exame de relação entre finalidades e meios, e seu sentido prático para o paciente, um encontro terapêutico de outra qualidade, mais humanizado.

\section{Metodologia}

O presente estudo caracteriza-se por uma pesquisa exploratória de campo, com enfoque qualitativo dos dados. Minayo et al (1994) afirma que, ao adotá-lo, não se persegue um critério de representatividade numérica, mas um aprofundamento e uma abrangência para compreender o fenômeno estudado. Afirmando que na pesquisa qualitativa a interação entre o pesquisador e os sujeitos pesquisados é essencial.

A estratégia pedagógica desenvolvida no curso foi a técnica de dramatização com o objetivo de promover a análise das representações acerca de experiências geradoras de sofrimento no ambiente de trabalho, a partir da representação de cenas geralmente constituídas no espaço de trabalho do profissional de enfermagem. Ou seja, as técnicas teatrais foram utilizadas tanto na construção do processo de conhecimento dos alunos-enfermeiros como um recurso de coleta de dados. A finalidade foi analisar de que maneira o cotidiano do trabalho em saúde gera sofrimento para os enfermeiros e como este sofrimento repercute na humanização da assistência.

Por se tratar de uma pesquisa de campo, os dados foram identificados, agrupados e analisados a partir de categorias que emergiram do diário de campo do pesquisador, sendo formuladas perguntas relacionadas aos objetivos da pesquisa, de acordo com a perspectiva da análise temática de conteúdo.

Os sujeitos do estudo foram trinta enfermeiros - alunos do Curso de Especialização em Enfermagem do Trabalho. A Pesquisa foi desenvolvida na Escola de Enfermagem Aurora de Afonso Costa da UFF - Universidade Federal Fluminense, na cidade de Niterói /RJ, no Curso de Especialização em Enfermagem do Trabalho, onde ministro a disciplina Psicologia do Trabalho. A escolha pelo cenário de estudo deu-se pelo fato de utilizar-se como prática pedagógica a técnica da dramatização como modo de expressão de experiências dos alunos relacionadas às temáticas propostas para discussão e aprofundamento pedagógico.

Como metodologia utilizou-se discussão sobre material teórico, vídeo, debate e a dramatização. A partir desta última estratégia metodológica, desenvolveu-se junto aos alunos uma dinâmica para abordar a questão do sofrimento do profissional de 
enfermagem. A partir da dramatização em grupo, os alunos puderam, na perspectiva da discussão coletiva, refletir sobre sua práxis profissional, considerando a temática em estudo.

A análise da dramatização se deu inicialmente considerando alguns pontos, tais como: o que aconteceu, que fatores determinaram esses acontecimentos, como os atores se sentiram no desempenho dos papéis. Contudo, ao final da dramatização foi feita uma discussão sobre as cenas, para constatar a estratégia como facilitadora da aprendizagem. Tal ação permitiu que os alunos deixassem de ser expectadores passivos, co-relacionando as cenas ao seu cenário de prática, oportunizando uma discussão sobre o tema abordado - sofrimento - e permitindo ao aluno identificar ações que comprometem uma prática humanizada.

A partir do texto 'A exploração do sofrimento', foram selecionadas a priori, quatro temáticas para discussão em grupo: a exploração da frustração; a exploração do sofrimento; a exploração da ansiedade e o costume. Estas temáticas deveriam ser relacionadas ao ambiente/cenário de prática profissional/trabalho (DEJOURS, 1992).

Após o tempo da leitura, foram dadas orientações a respeito da atividade proposta, em que eles deveriam, a partir da temática abordada pelo texto, refletir sobre a questão que correspondia a seu grupo e pensar em uma cena que justificasse sua resposta. Tiveram vinte minutos para pensar e construir a cena. Para apresentação, tiveram cinco minutos para dramatizar. Puderam utilizar qualquer recurso para representar algum elemento na cena: pessoas, objetos. A partir daí, os alunos tiveram liberdade para criar a cena, sem interferência do professor. Em seguida, cada grupo se organizou e estabeleceu as estratégias para a dramatização.

Nesta perspectiva, no âmbito da dramatização, o movimento dialético que oscilou do individual para o coletivo e do coletivo para o individual, possibilitou a construção do conhecimento comum. A riqueza das dinâmicas está principalmente na dialogicidade, o princípio norteador da dramatização, de onde emerge a crítica-reflexiva dos que participam produzindo dados para a pesquisa. As anotações do diário de campo enriqueceram as reflexões em sala de aula pelas vivências diferentes de cada enfermeiro, em virtude do tempo de formação e diferentes cenários de atuação profissional, mas todos estavam buscando formação na área de enfermagem do trabalho, servindo como objeto de estudo para uma análise empírica do resultado encontrado.

O sujeito produz sentido a partir das condições de produção dos discursos citados nos diferentes contextos de atuação profissional. Assim, seus enunciados 
tendem a ser diferentes, em função destes distintos contextos. Entretanto, a heterogeneidade dos alunos favorece o desvelamento, tanto dos limites quanto das possibilidades de cada cenário, para se manifestarem de forma criativa, quando submetidos a uma situação de dramatização.

Tendo em vista que o espaço da dramatização é caracterizado como um espaço plural, dialético e dialógico, em que os sujeitos aprendem e crescem. Nele emergiram as vivências e experiências dos sujeitos da pesquisa, carregadas de suas crenças, seus valores, suas visões de mundo, suas emoções, sua inserção sociocultural, manifestas nas contradições, nos conflitos ideológicos, nas semelhanças e diferenças de cada sujeito.

Deste modo, trabalhamos com a subjetividade manifesta no coletivo e na intersubjetividade.

A dramatização é uma estratégia de ensino que tem origem nos trabalhos desenvolvidos em Viena, pelo médico e sociólogo Jacob Lev Moreno. Que desenvolveu a técnica psicoterapêutica conhecida como psicodrama, que consiste na utilização da livre improvisação dramática, visando à catarse e ao desenvol vimento da espontaneidade do indivíduo. Alguns dos princípios do psicodrama passaram a ser utilizados também com objetivos educacionais, dando origem ao psicodrama pedagógico, que se caracteriza, sobretudo pela dramatização (GIL, 1997, p.91).

Alvim e outros (2001, p. 191) comentam que:

Trabalhando no plano da subjetividade, numa atmosfera coletiva, dialógica e plural com a que se estabelece no ambiente criativo e sensível das dinâmicas de criatividade e sensibilidade, é possível para o pesquisador e os sujeitos ampliarem suas formas de argumentação e os seus entendimentos acerca do outro, uma vez que na enunciação do "discurso do outrem", encontramos os nexos com o nosso próprio discurso.

Deste modo, concorda-se com Freire (1987), quando diz que não há diálogo se não há uma imensa fé nos homens. Fé no seu poder de fazer e de refazer, de criar e recriar. O homem dialógico tem fé nos homens antes de encontrar-se frente a frente com eles. Ele que é crítico, sabe que, se o poder fazer, de criar, de transformar é um poder dos homens, sabe também que podem eles, em situação concreta, ter este poder prejudicado. Esta possibilidade, em lugar de matar no homem dialógico a sua fé nos homens, faz aparecer nele, pelo contrário, um desafio ao qual tem de responder. A riqueza das dinâmicas está principalmente na dialogicidade, o princípio norteador da dramatização, de onde emerge a crítica-reflexiva dos que participam produzindo dados para a pesquisa. 
Vugman e outros (2006) apontam a utilização da dramatização no ensino, em que o aluno é levado a expressar suas percepções e sensações a respeito da realidade, revelando desta forma seu entendimento e saber a respeito de determinado conteúdo. Para o autor, a dramatização constitui-se como núcleo do psicodrama. Ela mobiliza no aluno sua espontaneidade, suas capacidades intelectuais, afetivas e sociais no ato de aprender. A dramatização favorece não apenas a aquisição de conhecimento, como também o desenvolvimento de relações interpessoais adequadas e saudáveis. A participação do aluno na ação dramática torna-o sujeito do seu conhecimento. Ao utilizar a dramatização como recurso pedagógico, o processo propicia ao aluno a possibilidade de desenvolver-se como ser humano, conjugando razão e emoção.

Percebe-se que a dramatização, cada vez mais, vem sendo incorporada por educadores envolvidos na formação profissional do enfermeiro. Barros e outros (2006) referem, contudo, que esta incorporação, muitas vezes, vem ocorrendo com objetivo de aprendizagem das práticas e conceitos de enfermagem. A utilização do recurso da dramatização no processo ensino-aprendizagem, deve estar integrada ao processo de ensinar e aprender da enfermagem. A dramatização pode não só levar os enfermeiros a perceberem que é preciso adquirir flexibilidade, como também pode auxiliar na aquisição de uma qualidade de escuta. Na área de enfermagem, cada vez mais, percebese a preocupação de professores em utilizar novas estratégias de ensino, que acompanhem às grandes transformações. A dramatização além de buscar a reflexão de novas estratégias no processo de aprendizagem, enfatiza a percepção dos alunos sobre o conhecimento e a autonomia. Favorece o desenvolvimento do pensamento crítico, o que é um desafio para professores e alunos, pois exige mais que o uso de técnicas de ensino; exige, sobretudo, a participação crítica.

Cabral (2007) apresenta como proposta de aprendizagem a utilização da técnica teatral em sala de aula. Refere que a manifestação teatral, desde suas origens rituais, tem se constituído num eficaz meio de comunicação e discussão das questões humanas.

Lucca e outros (2004) apontam o psicodrama como uma abordagem qualitativa para o estudo da saúde do trabalhador, utilizando-o como um instrumento de coleta de dados das condições e organização do trabalho, apesar de ter inúmeras aplicações, podendo ser empregado nos diferentes contextos organizacionais e institucionais. Além de colocar em questão um novo modelo de coleta de dados em pesquisa qualitativa, no campo de aplicação do psicodrama, os autores oferecem 
insumos para outros profissionais. Reforçam que sua utilização contribui inclusive para a melhoria da qualidade de vida da população trabalhadora, através de diagnóstico das condições e organização do trabalho, na medida em que oferece subsídios que contribuem para a redução de doenças ocupacionais e acidentes do trabalho. Enfim, o psicodrama revela sua eficácia terapêutica como instrumento de intervenção, na medida em que promove espaços de fala, escuta e desenvolvimento da percepção de si e do outro, assim como reflexões sobre o processo de trabalho, contribuindo desta forma para a melhoria de aspectos relacionados à organização do trabalho.

\section{Análise e discussão dos Resultados}

Para analisar os dados obtidos, buscou-se respaldo na Teoria Social da Análise do Discurso (AD), proposta por Mikhail Bakhtin, pelo fato de este método defender que o ser humano, fora das condições sociopolíticas objetivas e fora de um dado contexto social, não tem nenhuma existência. Para o autor o homem precisa de um nascimento social, pois o simples nascimento biológico não é o suficiente para sua participação histórica. Sua visão de mundo constitui-se no direito à liberdade e, sobretudo, no respeito ao ser humano (BAKHTIN, 1999).

A palavra ganha um lugar de destaque na constituição da consciência, sua função de signo, como fenômeno ideológico, constitui-se como um modo mais puro e sensível de relação social. A palavra, para Bakhtin, está sempre impregnada de conteúdos ou de sentidos ideológicos. Não recebemos, portanto, a língua pronta para o uso - penetramos na comunicação verbal, mas apenas quando inserimo-nos nessa corrente é que nossa consciência desperta e começa a operar. A linguagem, num viés de totalidade, está integrada na vida humana. Sendo, portanto, o verdadeiro espaço de recuperação e produção do sujeito como ser histórico e social. Contudo, o uso das palavras na comunicação depende sempre de um discurso particular. A experiência discursiva de cada sujeito é desenvolvida em uma constante interação dialogicidade. A vivência como algo determinado não é praticada pelo sujeito, portanto volta-se a um sentido, a um objeto, a um estado. Não para si mesmo, mas para a plenitude de sua presença na alma. Assim:

Devo fazer de meus vivenciamentos um objeto especial de meu ativismo para vivê-los. Devo abstrair dos objetos, fins e valores para os quais estava endereçado o vivenciamento vivido e os quais assimilaram e completaram esse vivenciamento, para sobreviver a 
sua própria vivência como algo determinado e presente (BAKHTIN, 2003, p. 103).

Com base no material analisado, os dados foram agrupados em duas categorias de análise:

\section{A primeira categoria diz respeito aos problemas enfrentados pelos} enfermeiros no cenário de prática, efeitos sobre o processo do cuidado.

O cotidiano do trabalho no cenário de prática é representado pelos enfermeiros pela idéia da falta de recursos materiais, de trato da chefia interação adequada, modelo adequado de gestão dos processos de cuidado, de treinamento/educação continuada, de avaliação e de mudança pra valer.

A falta de recurso de material e de condições adequadas de trabalho é apontada como um dos problemas que mais afetam o processo de cuidados. Já no início da primeira cena analisada, diz-se que (...) equipe não dispõe a tempo de materiais necessários e a paciente vem a óbito.

A falta de trato/flexibilidade da chefia de enfermagem com os membros da equipe de enfermagem, pode mesmo ser caracterizada como um assédio moral. (...) se você quiser, pode ir agora mesmo à divisão de enfermagem e pedir suas contas, não vai fazer falta por aqui. Diante de tal discurso, que sentimentos poderiam surgir no sujeito senão ansiedade, raiva e frustração? Podemos perceber a que ponto chega a manifestação do poder dentro da equipe de enfermagem.

A falta de treinamento adequado é evidenciada pelo treinamento centrado em procedimentos técnicos, sem contemplar aspectos mais abrangentes do processo de cuidar como: acolhimento, interação, trabalho em equipe e vínculo. $\mathrm{O}$ treinamento espelha-se no próprio modelo tradicional de formação das enfermeiras o tecnicista. $\mathrm{Na}$ cena apresentada, o enfermeiro apresenta um técnico de uma empresa que fará o treinamento com a equipe de enfermagem. (...) ele não deu o treinamento direito. Ele falava rápido. Perdemos a paciente por falta de competência e insegurança.

A mudança é apontada como solução para problemas que não foram devidamente discutidos/analisados pela equipe. Por detrás do discurso de mudança há, na verdade, um continuísmo da mesma forma de poder. O autoritarismo apresenta-se dissimulado/disfarçado de mudança. É apenas uma nova roupagem, um álibi para um antigo modo de gestão a autoritária. Tal fato gera resistência, sensação de incapacidade, falta de competência e de compromisso para desenvolver ações de cuidado. 
A falta de avaliação do processo de ensino-aprendizagem nos treinamentos realizados e da própria prática de cuidar impede que a experiência de cuidar/descuidar dos enfermeiros seja tomada como ponto de partida para processos de mudanças. Nas cenas apresentadas por três grupos revelam-se falhas no processo de acompanhamento e avaliação, tanto dos cuidados prestados quanto dos processos de capacitação desenvolvidos, conforme observamos nos discursos a seguir: A equipe não dispõe a tempo dos materiais necessários e a paciente vem a óbito. Estamos tendo um probleminha com os técnicos(...).

A avaliação, como prática de investigação, é um processo de reflexão sobre e para a ação, contribuindo para que o cuidador se torne cada vez mais capaz de recolher indícios, de atingir níveis de complexidade na interpretação de seus significados e de incorporá-los como eventos relevantes para a dinâmica de trabalho (ESTEBAN, 2001).

Entendemos assim que, se apropriando da avaliação investigativa, o trabalhador de enfermagem refina seus sentidos e desenvolve diversos conhecimentos, passando a agir conforme as necessidades reais de ensino ou de cuidado dos sujeitos. Assim, ele torna-se capaz de dialogar com a complexidade e singularidade dos sujeitos, com a multiplicidade de conhecimentos, favorecendo a promoção de sua autonomia.

No que diz respeito aos efeitos sobre o paciente, constata-se que a falta vivida pelos enfermeiros gera muitas vezes raiva, ressentimento, frieza, descompromisso com o processo de cuidado e desvalorização do paciente enquanto sujeito, contribuindo para a desumanização da assistência, cujo efeito fundamental é o desamparo do próprio paciente. Deste modo, a ação pode ser qualificada por um julgamento do pensamento, o que se define como ética, ou seja, toda ação humana que toma por objetivo de intervenção outra ação humana, do próprio agente ou de um outro. Neste sentido, ética é um feito e um discurso (COSTA,1994).

O trabalho em saúde é um trabalho de escuta, em que a interação entre profissional de saúde e usuário é determinante da qualidade da resposta assistencial. A incorporação de novidade tecnológica é premente e constante, e novos processos decisórios repercutem na concretização da responsabilidade tecnocientífica, social e ética do cuidado, do tratamento ou do acompanhamento em saúde (CECCIM et $a l, 2004)$.

O PNHAH discute a necessidade de humanizar o cuidado, a assistência, a relação com o usuário do serviço de saúde, destacando ser preciso valorizar os diferentes 
sujeitos implicados no processo de produção de saúde: usuários, trabalhadores e gestores. Com base nos dados aqui analisados evidenciamos como as demandas reprimidas dos enfermeiros afetam o cuidado prestado por esses profissionais. Como todo trabalho, esse é produzido por sujeitos e produtor de subjetividade. Não há humanização da assistência sem cuidar da realização pessoal e profissional dos que a fazem. Não há humanização sem um projeto coletivo em que toda a organização se reconheça e, nele, se valorize. Assim, reforça-se a importância de identificar as necessidades sociais de saúde dos próprios trabalhadores como meio de humanizar os cuidados em saúde.

A segunda categoria diz respeito aos métodos empregados pelos enfermeiros em sua prática e seus efeitos sobre o processo do cuidado.

Constata-se que o modelo retratado pela enfermagem como em operação em seu cotidiano de cuidar é o biomédico. Neste modelo, a técnica, a medicalização do sofrimento e o saber médico assumem a centralidade dos processos de cuidados. A partir desta idéia central, podemos depreender duas categorias de análise: o cuidar tardio/descuidado e o domínio das emoções como método de trabalho.

A emergência do cuidar tardio/descuidado, o modelo biomédico parece espelhar sua falência para dar conta dos problemas enfrentados no cotidiano do cuidar, mas seu uso persiste como se isso fosse natural. Outros sinais de sua hegemonia e operação pela prática de enfermagem são vistos no depoimento a seguir: (...) O enfermeiro chama o médico e este chega perguntando: o que aconteceu? Adrenalina, adrenalina, adrenalina. Importante salientar que a solução é buscada na medicação, mas é a falta de tempo, planejamento e de material que acaba determinando o desfecho da história: o óbito. Evidencia-se aqui a falta de eficácia do modelo de cuidar vigente. O fato do setor de emergência ser o espaço social escolhido para representar a frustração no processo de cuidado mostra que a experiência em análise é vivenciada pelo sujeito de uma forma crítica, emergencial e desesperada, requerendo uma solução imediata. O chefe como aquele que aguarda espera sentada que o problema se resolva.

O domínio das emoções como método de trabalho, destaca-se na cena em que a postura de uma aparente docilidade da equipe de enfermagem frente à crise ocasionada pela organização do trabalho. Nela o trabalho é apresentado em sua forma caótica, marcado pela lógica do poder e da dominação (...) O técnico de enfermagem chora enquanto o restante da equipe se mantém muito agitada. Um membro da equipe dirige- 
se a ele pedindo para não chorar. Observou-se, durante a dramatização, todos os participantes riram.

Constata-se que a experiência vivida pela enfermagem é assimilada como sofrimento extremo, traduzido pelo choro de um membro da equipe e sua repressão pelo outro. A impotência diante da morte e falência da possibilidade de cuidar é traduzida em forma de riso resposta emocional paradoxal diante do real, mas capaz de expressar o sofrimento vivido no coletivo diante da impotência/poder de um dado modo de agir que não protege o paciente da morte. A experiência da morte do outro/paciente denuncia a própria falência dos métodos empregados pelos profissionais, que de certa forma representa para o sujeito/trabalhador a própria morte.

Paradoxalmente, o sofrimento da equipe é silenciado o choro é repreendido. O amparo que talvez possa ocorrer será de ordem estritamente pessoal e individual, entre alguns componentes e não como um método de trabalho em equipe, não se traduzindo em uma ação no coletivo. A frieza congelamento das emoções da equipe causada pela prática submissa e ineficaz e pela impossibilidade de expressão dos sentimentos dos trabalhadores, pode explicar o afastamento do enfermeiro em relação ao paciente e sua recusa em considerá-lo como sujeito.

A ética do cuidado se sustenta basicamente em respeitar o sofrimento, bem como a autonomia do sujeito. Para tanto, é preciso estabelecer bases sólidas e normas éticas de cuidados, que respeitem em todos os casos o sentido da dignidade humana (TAQUECHEL et. al, 2006).

O poder disciplinar assume um caráter visível na cena apresentada por meio da relação hierárquica de poder. Criar um espaço social em que se afirmam as relações interpessoais é uma tarefa imprescindível para aqueles que buscam problematizar seu papel social.

Os dados acima reforçam um outro aspecto-desafio do PNHAH, a superação do tecnicismo, o sentimento que a suposição de objetividade e neutralidade da ciência desperta no homem moderno. O desenvolvimento científico e tecnológico tem trazido uma série de benefícios, sem dúvida, mas tem como efeito colateral a inadvertida promoção da desumanização. Com a suposta objetividade da ciência pode-se perceber a eliminação da condição humana da palavra, da palavra que não pode ser reduzida à mera informação. $\mathrm{O}$ ato técnico, por definição, elimina a dignidade ética da palavra, pois essa é necessariamente pessoal, subjetiva e precisa do reconhecimento na palavra 
do outro. A dimensão desumanizante da ciência e tecnologia se dá, portanto, na medida em que se fica reduzido a objetos da própria técnica e objetos despersonalizados de uma intervenção que se propõe fria e objetiva.

\section{Considerações Finais}

Ao ser oferecido a oportunidade do lúdico para representar papéis em um processo de dramatização, o sujeito gera possibilidade de transformar a realidade em que se encontra. $O$ enfermeiro frente a situação da dramatização, representa simbolicamente aquilo que gostaria que de fato acontecesse em sua prática profissional e inconscientemente expressa aquilo que mais lhe afeta, bem como aquilo que nem percebe que lhe faz sofrer.

A dinâmica subjacente ao processo de humanização dos enfermeiros em seu cenário de prática é marcada por faltas, que simbolizam a carência histórica de valorização desses profissionais junto à sociedade, uma vontade de potência. Dois dos efeitos desse desprestígio são: a violência, que marca as formas de relação entre os próprios membros da equipe de enfermagem, e o descaso/abandono do paciente tudo isto com grande sofrimento para os enfermeiros. Compreendemos ser este um dos desafios com o qual o PNHAH se depara, constituindo um problema que afeta diretamente a organização do processo de trabalho em saúde e consequentemente o processo de cuidar nos serviços de saúde.

A dimensão prática do saber da enfermagem e a divisão técnica do trabalho são componentes fundamentais para explicar a crise de poder vivenciada pelos trabalhadores de enfermagem, no cenário de prática.

Essa perspectiva nos leva a pensar que o processo do cuidado situa-se entre dois pólos: o de resgatar para o sujeito/enfermeiro o lugar na clínica/cuidado que este perdeu e o do direito ao cuidado, que faz com que o sujeito/paciente passe a se sentir cada vez mais empoderado e respeitado no processo de cuidado.

\section{Referências Bibliográficas}

ALDRIGHETTI, S. M.; ZÚÑIGA, G. E. Necessidade de recuperar la naturaleza ética del cuidado de enfermería. Revista Adecra - Visión de Enfermería Actualizada. Buenos Aires, año I, n², p. 5-7, junio. 2005.

ALMEIDA, M.C.P. A Formação do Enfermeiro frente à Reforma Sanitária. Cadernos de Saúde Pública, RJ, 2(4): 505-510, out/dez, 1986.

ALVIM, N. A. T.; CABRAL, I. E. A aplicabilidade das plantas medicinais por enfermeiras no espaço do cuidado institucional. Esc. Anna Nery Rev. Enfer., v. 5. n², ago. 2001. 
AYRES, J. R. C. M. Cuidado e Humanização. In DESLANDES S. F. (Org.) Humanização dos cuidados em saúde: conceitos, dilemas e práticas. Rio de Janeiro: ed. FIOCRUZ, 2006.

BAKHTIN, M.M. Estética da criação verbal. Introdução e tradução do russo Paulo Bezerra: Prefácio à edição francesa Tzvetan Todorov. - $4^{\mathrm{a}}$ ed. - São Paulo: Martins Fontes, 2003.

Marxismo e filosofia da linguagem: problemas fundamentais do método

sociológico na ciência da linguagem. - $12^{\mathrm{a}}$ ed. São Paulo: Hucitec, 1999.

BARROS, M. A; CYRILLO, C. C. P. A dramatização como recurso no processo ensinoaprendizagem na disciplina de história da enfermagem. Cogitare enfermagem, v.11, n.1. Curitiba, 2006.

BENEVIDES, R.; PASSOS, E. Humanização na saúde um novo modismo? InterfaceComunicação, Saúde, Educação, v. 9, n¹7, mar/ago, p. 389-394, 2005.

BRASIL. Programa Nacional de Humanização da Assistência Hospitalar (PNHAH). Brasília/DF. Ministério da Saúde, 2002.

CABRAL, O. Teatro na sala de aula: uma proposta de aprendizagem. Sociedade Brasileira para o progresso da Ciência - SBPC, 2004.

CECCIM, R.B.; FEUERWERKER, L. O Quadrilátero da Formação para a Área da Saúde: Ensino, Gestão, Atenção e Controle Social. PHYSIS: Rev. Saúde Coletiva, Rio de Janeiro, 14(1): 41- 65, 2004.

COLLET N.; ROZENDO C. A. Humanização e Trabalho na enfermagem. Revista Brasileira de Enfermagem, 56(2): 189-292, 2003.

COSTA, J, F. A ética e o espelho da cultura. Rio de Janeiro: Rocco, 1994.

DEJOURS C. A loucura do trabalho: estudo de psicopatologia do trabalho. $5^{\mathrm{a}} \mathrm{ed}$ ampliada. São Paulo: Cortez-Oboré, 1992.

DESLANDES S. F. Análise do discurso oficial sobre humanização da assistência hospitalar. Ciência e Saúde Coletiva, 9(1) 7-14, jan-mar 2004.

ESTEBAN, M T (org.). Avaliação: uma prática em busca de novos sentidos. 3a ed. Rio de Janeiro: DP \&A; 2001.

FERREIRA, J. M; MISHIM, S. M. O processo de municipalização da saúde sob o olhar do ser humano-trabalhador de enfermagem da rede básica de saúde. Revista Latino-American de Enfermagem, 12(2): 212-20, mar-abr, 2004.

FREIRE, P. Pedagogia do Oprimido. São Paulo: Paz e Terra, 1987.

GASTALDO, D. Humanização como processo conflitivo e contextual. Interface Comunicação, Saúde, Educação, v. 9, n 17: mar/ago : p. 395-397, 2005.

GERMANO, R.M. Educação e ideologia da enfermagem no Brasil. 2a. Ed. São Paulo: Cortez, 1985.

GIL, A. C. Metodologia do ensino Superior. $3^{\text {a }}$. Ed. São Paulo: Atlas, 1997.

LIMA, A.M.C; MENDONÇA FJ.B.; DENIZ, J.S.S. Insuficiência Renal Crônica- A trajetória de uma prática. In: Org. Romano, B.W. A Prática da Psicologia nos Hospitais. São Paulo: Pioneira, 1994.

LUCCA, S. R.; SCHMIDT, M. L G. Psicodrama: Uma abordagem metodológica qualitativa para o estudo da saúde do trabalhador. Psicol. Am. Lat. Ago., n², p. 0-0, 2004.

MINAYO, M.C.; DESLANDES, S.F.; NETO, O.C.; GOMES, R. Pesquisa Social. Teoria, método e criatividade. Petrópolis, RJ: Ed. Vozes, 1994.

OLIVEIRA, B.R.G; COLLET N; VIEIRA, C.S. A humanização na assistência à saúde. Rev. Latino-am Enfermagem, março-abril; 14(2): 277-84, 2006.

SANTOS, T.C. ; SEBASTIAN, R.W. Acompanhamento Psicológico à pessoa portadora de doença. In: CAMON, W.A. A. (ORG.) E a Psicologia entrou no Hospital. São Paulo: Pioneira, 1996.

TAQUECHEL, M.L. Relación de la ética del cuidar y los modelos de enfermería con la persona y su dignidad. Rev Cubana Enfermer, 22(1), 2006.

TAVARES, C.M.M. A educação na formação da enfermeira em saúde mental. Rev. Enf. UERJ. Rio de Janeiro, 2002a.

TAVARES, C.M.M. Paradigmas das diretrizes curriculares e a enfermagem. Cad CE ; 4: 121127, 2002b. 
TREVISAN, M.A.; MENDES, I. A.C.; LOURENÇO, M.R.; MELO, M.R.A.C. Al encuentro de la competencia del cuidade según Boff: una nueva perspectiva de conducta ética de la enfermera gerente. Rev-am Enfermagem, 11(5): 652-7, set-out, 2003.

VUGMAN, V.N.; RUBINI, C. Dramatização no ensino de Física Moderna. XVI Simpósio Nacional de Ensino de Física, Rio de Janeiro, 2005.

WATSON, J. Nursing: the philosophy and science of caring. Boston: Little Brown, 1979.

ZOZAYA, J.L.G. El medico y el paciente en el contexto de la enfermidad cronica. Revista Centro Policlan Valência, 3(1): 117-119, ene-jun, 1985. 